\title{
CAMPANHA SANITÁRIA E EDUCAÇÃO EM CIÊNCIAS PARA A SAÚDE: CONSTRUC̣ÃO DE SENTIDOS SOBRE IMPRESSO PARA 0 COMBATE A TRANSMISSÃO NÃO VETORIAL DO ZIKA VÍRUS
}

\author{
JEFFERSON SILVA COSTA ${ }^{*}$ \\ https://orcid.org/0000-0002-1771-3475 \\ ANA MARIA DOS ANJOS CARNEIRO-LEÃO" ** \\ https://orcid.org/0000-0002-8815-8624
}

RESUMO: A pesquisa objetiva analisar a construção de sentido sobre um impresso de combate ao Zika vírus por Licenciandos em Ciências Biológicas após formação sobre a Gramática do Design Visual (GDV). A GDV propõe uma análise multimodal considerando a interação verbo-visual com o contexto social. A pesquisa foi dividida em: I) análise do impresso; II) questionário; III) curso sobre GDV e Multimodalidade; IV) propostas de alterações ao impresso. A análise proporcionou reflexões sobre o uso do impresso na Educação em Ciências. As respostas ao questionário reforçaram a importância de letrar multimodalmente professores. Após a formação, os licenciandos apresentaram dificuldades para compreender algumas das funções da GDV, contudo, as propostas de alteração demonstraram impacto positivo do curso na construção de sentido.

Palavras-chave: Campanhas sanitárias; Multimodalidade; Formação de professores.

CAMPAÑA SANITARIA Y EDUCACIÓN EN CIENCIAS PARA LA SALUD: CONSTRUCCIÓN DE SENTIDOS ACERCA DE UN IMPRESO PARA EL COMBATE A LA TRANSMISIÓN NO VECTORIAL DEL VIRUS DEL ZIKA

RESUMEN: La investigación tiene el objetivo de analizar la construcción de sentido acerca de un impreso de combate al virus del Zika por estudiantes de formación docente en Ciencias Biológicas después de una formación sobre la Gramática del Design Visual (GDV). La GDV propone un análisis multimodal considerando la interacción verbovisual con el contexto social. Se dividió

${ }^{*}$ Mestre, Universidade Federal
Rural de Pernambuco (UFRPE).
Professor IA da Rede Pública
na Escola Técnica Estadual
Ariano Vilar Suassuna, Município
de Garanhuns-PE, Brasil. Grupo de
Pesquisa Práticas de Ensino.
E-mail: jefferson.sicosta@professor.
educacao.pe.gov.br
**Doutora, Universidade Federal
do Paraná (UFPR). Professor
Associado 4 na Universidade
Federal Rural de Pernambuco
(UFRPE), Recife-PE, Brasil.
Grupo de pesquisas biologia
sistêmico-complexa.
E-mail: ana.maria.ppgec@gmail.com

${ }^{*}$ Mestre, Universidade Federal Prol de Pernambuco (UFRPE). Professor IA da Rede Pública Ariano Vilar Suassuna, Município de Garanhuns-PE, Brasil. Grupo de Pesquisa Práticas de Ensino. educacao.pe.gov.br

outora, Universidade Federal do Paraná (UFPR). Professor Associado 4 na Universidade (UFRPE) Recife-PE, Brasil. (UFRPE), Recife-PE, Brasil.
Grupo de pesquisas biologia sistêmico-complexa. E-mail: ana.maria.ppgec@gmail.com

I Escola Técnica Estadual Ariano Vilar Suassuna, Garanhuns, PE - Brasil.

II Universidade Federal Rural de Pernambuco, Recife, PE - Brasil. 
la investigación en: I) análisis del impreso; II) cuestionario; III) curso sobre GDV y Multimodalidad; IV) propuestas de alteración del impreso. El análisis proporcionó reflexiones acerca del uso del impreso en la Educación en Ciencias. Las respuestas al cuestionario reafirmaron la importancia de alfabetizar multimodalmente los profesores. Después de la formación, los estudiantes presentaron dificultades para comprender algunas de las funciones de la GDV, sin embargo, las propuestas de alteración demostraron el impacto positivo del curso en la construcción de sentido.

Palabras clave: Campañas sanitarias; Multimodalidad; Formación de profesores.

\section{SANITARY CAMPAIGNS AND EDUCATION IN SCIENCES FOR HEALTH: CONSTRUCTION OF SENSE ABOUT PRINTED FOR THE COMBATING NO VETORIAL TRANSMISSION OF ZIKA VIRUS}

ABSTRACT: The research aims to analyze the construction of meaning on a form to fight the Zika virus by Graduates in Biological Sciences after training on the Grammar of Visual Design (GDV). GDV proposes a multimodal analysis considering the verbal-visual interaction with the social context. The research was divided into: I) analysis of the form; II) questionnaire; III) course on GDV and Multimodality; IV) proposals for changes to the form. The analysis provided reflections on the use of the form in Science Education. The responses to the questionnaire reinforced the importance of multimodal literacy teachers. After the training, the undergraduate students had difficulties to understand some of the functions of GDV, however, the proposed changes showed a positive impact of the course in the construction of meaning. Keywords: Sanitary campaigns; Multimodality; Formation of teachers. 


\section{CAMPANHAS SANITÁRIAS E EDUCAÇÃO EM CIÊNCIAS PARA A SAÚDE}

As Campanhas Sanitárias, compostas por impressos de promoção à Saúde, são aquelas que visam à orientação para o cuidado com a própria saúde ao invés do incentivo ao consumo (ROCHA e FELTES, 2016). Esse tipo de campanha está pautado em um modelo idealizado por Oswaldo Cruz no início do século XX, denominado de "Sanitarista Campanhista".

Apesar do modelo ser antigo, Silva et al. (2010) destacam que apenas a partir dos anos de 1980 o diálogo passou a figurar como potencial propulsor em impressos de Educação em Saúde. Essa modificação ocorreu em função dos movimentos populares eclodidos ao final do regime militar, que incentivaram especialistas em saúde a desenvolverem trabalhos considerando a realidade das classes populares (VASCONCELOS, 2015).

Falkenberg et al. (2014) salientam que um dos principais influenciadores dessas modificações foi o educador Paulo Freire, que defendia a necessidade de uma educação menos verticalizada e muito mais dialógica, batizada de Educação Popular, com este conceito transposto para a Educação em Saúde.

A ideia de uma Educação Popular em Saúde surgiu da necessidade de se construir um elo entre a educação técnico-científica e o saber popular. A partir disso, o objetivo educativo seria auxiliar as camadas populares na conquista de sua autonomia e de seus direitos (FALKENBERG et al., 2014), sendo a saúde um deles. Ou seja, os impressos de Educação em Saúde, com base neste novo modelo, devem ser vistos como instrumentos mediadores das relações entre educador e educandos.

No entanto, para Valla (2006), os governos brasileiros ainda agem, em pleno século XXI, de forma autoritária, decidindo unilateralmente a respeito dos problemas de saúde pública que merecem atenção, grau de investimento em cada epidemia e o tom das campanhas sanitárias, e, por consequência, seus impressos. O autor destaca que muitas dessas campanhas sanitárias tendem a conclamar a população para exterminar um determinado vetor biológico, individualizando a questão. Ou seja, se o culpado direto pelo adoecimento é o vetor, o indireto seria a população, que não executou o conjunto de ações solicitadas nas campanhas. Isso é conhecido por "culpabilização da vítima” (VALLA, 2006, p. 53).

Caminhando nesta direção, Almeida Júnior (2000) atenta que devemos considerar os recursos visuais, que se fazem presentes nesses impressos de Educação em Saúde, enquanto discursos informativos para a sociedade, pois eles podem ser responsáveis "por mecanismos de reitificação do sujeito educando, [e] devem ser considerados como modelo instituinte de realidades" (p.19).

Charaudeau (2013) pontua ainda que uma campanha sanitária "visa a dissuadir os indivíduos, que vivem em sociedade, de manter um comportamento prejudicial à coletividade, sendo necessária a adoção de outro comportamento" (p. 383). Dessa forma, é preciso refletir sobre a necessidade de preparar os professores para trabalhar com esse tipo de campanha, especialmente porque muitos dos impressos que as compõem são indicados por órgãos ligados aos Governos Federal, Estadual e/ou Municipal como fontes de informações. 
Este alerta torna-se ainda mais contundente quando consideramos um estudo desenvolvido por Freitas e Rezende-Filho (2011), que buscou analisar, em artigos científicos nacionais, os modelos de comunicação em impressos utilizados como estratégia educativa na saúde. Dos onze artigos encontrados pelos autores, nove continham impressos de campanhas sanitárias que reforçavam o modelo de que o sujeito a ser educado é apenas um consumidor das práticas ali presentes.

Claro que este estudo simboliza apenas um recorte de toda a amplitude de campanhas sanitárias veiculadas no cenário nacional, porém, revela uma tendência preocupante desses instrumentos, fortalecendo a preocupação a respeito da necessidade de uma "Educação Popular em Saúde" (VASCONCELOS, 2015).

Apesar disso, faz-se necessário determinar o termo "Educação em Saúde" como majoritário, sobretudo em função das recomendações oficiais da Biblioteca Virtual em Saúde (BVS), vinculada ao Ministério da Saúde (FALKENBERG et al., 2014), cabendo à Educação Popular ser entendida como referencial teórico que deve permear a Educação em Saúde (VASCONCELOS, 2015).

No contexto deste trabalho, nós ampliamos essa concepção para "Educação em Ciências para a Saúde" por considerarmos que, apesar das temáticas relacionadas à saúde serem temas transversais, cabe, de forma mais específica, à Educação em Ciências o trabalho com doenças que acometem populações humanas (BIZZO, 2009).

Ou seja, a Educação em Saúde, no contexto da educação básica, é permeada por um grupamento de conceitos científicos biológicos - tais como agente etiológico, vetor e ciclo biológico - que estão presentes nos materiais educativos distribuídos pelos órgãos governamentais para trabalho em escolas (BIZZO, 2009; MORAES e ANDRADE, 2009). Dessa forma, os estudantes necessitam compreender tais conhecimentos biológicos e, por vezes, eles são relegados ao segundo plano, precisando a Educação em Ciências se fazer tão presente quanto a Educação em Saúde.

Dessa forma, este trabalho foi desenvolvido partindo da compreensão de que o professor de Ciências e Biologia, por discutir questões relacionadas à saúde na sua sala de aula, é também um profissional de promoção da saúde, que, muitas vezes, recorre aos conceitos científicos biológicos para explicar fenômenos de saúde e doença.

A partir disso, compreendemos a Educação em Ciências para a Saúde como uma intersecção entre Educação em Ciências e a Educação em Saúde, tendo o professor como profissional majoritário. Por conta disso, é crucial ponderar que o profissional da Educação em Ciências para a Saúde que irá utilizar uma campanha sanitária não considere o educando apenas como o "público-alvo", sendo preciso compreendê-lo como sujeito do conhecimento e, por conseguinte, incentive este sujeito não apenas a aplicar os materiais como também a promover alterações no sentido de aproximá-los de seu cotidiano, rompendo a lógica transmissional corriqueiramente adotada neste tipo de material (FREITAS e REZENDE-FILHO, 2011).

Para tanto, é preciso considerar que estas campanhas e seus impressos são movidos por doenças com maior incidência e prevalência em um dado momento histórico, sendo convencional utilizar uma delas para garantir que as discussões estejam relacionadas à realidade. De posse deste entendimento optou-se por escolher a transmissão não-vetorial do Zika vírus. 


\section{A TRANSMISSÃO NÃO VETORIAL DO ZIKA VÍRUS}

Os primeiros casos de Zika vírus começaram a ser relatados, no Brasil, em 2016, no entanto, para Puccioni-Sohler et al. (2017) houveram relatos confirmados dessa doença, antes da publicação dos relatórios oficiais, no interior do estado da Bahia. Ou seja, é possível que a negligência com as primeiras ocorrências do Zika vírus possa ter acarretado o surto epidêmico de 2016, sobretudo se considerarmos que seu principal vetor em território nacional - o Aedes aegypti - é adaptado aos grandes centros urbanos.

A partir disso, é possível inferir que há certa necessidade de controle da proliferação do vetor biológico, conforme atentam Puccioni-Sohler et al. (2017) ao afirmarem que essa é uma das iniciativas cruciais para evitar a vasta e acelerada disseminação do Zika vírus, que pode causar alguns agravos de ordem neurológica.

Contudo, é preciso considerar o processo de transmissão do Zika vírus ocorre também pela via sexual (VALLE, PIMENTA e AGUIAR, 2016), o que transforma a doença em uma Infecção Sexualmente Transmissível (IST).

Foy et al. (2011) documentaram, em 2008, o primeiro caso de transmissão sexual do Zika vírus, quando dois cientistas estadunidenses contraíram a infecção durante o desenvolvimento de um estudo na aldeia de Bandafassi, no sudeste do Senegal. A suspeita de transmissão sexual ocorreu quando a cônjuge de um dos pesquisadores adoeceu, com sintomatologia compatível a doença, nove dias após o retorno do marido à cidade do Colorado, nos Estados Unidos (FOY et al., 2011), sem ter estado em área de ocorrência do vetor.

A hipótese foi reforçada posteriormente, em 2013, quando foi documentada a presença de partículas ativas do vírus no sêmen de um homem no Tahiti (VALLE, PIMENTA e AGUIAR, 2016), além de outros casos que veem sendo encontrados e documentados na literatura nos últimos anos (ATKINSON et al., 2016; D’ORTENZIO et al., 2016; MUSSO et al., 2015), endossando os relatos iniciais e contrariando o entendimento de que um Flavivirus, agente etiológico dessa doença, não seria transmitido por vias alternativas à vetorial (VALLE, PIMENTA e AGUIAR, 2016).

É preciso, portanto, além de retomar um processo de sensibilização, através de campanhas sanitárias sobre a eliminação do $A$. aegypti, compreender a necessidade de discutir o processo de transmissão não vetorial do Zika vírus. Nesse sentido, os impressos das campanhas sanitárias são instrumentos que precisam ser considerados como elementos repletos de signos visuais e verbais que podem ser utilizados pelos professores na sala de aula, sendo necessário discutir a importância de uma formação multimodal.

\section{MULTIMODALIDADE, FORMAC̣ÃO DE PROFESSORES E A GDV}

Moraes e Andrade (2009) destacam a necessidade da Educação em Ciências compreender que o mundo encontra-se imerso em diferentes tipos e formas de linguagem, não devendo essa discussão ficar restrita à disciplina de língua portuguesa. No entendimento dessas autoras ler e escrever são processos que ultrapassam a mera decodificação de signos linguísticos, sendo necessária a inserção dos mais variados tipos de textos, como as campanhas sanitárias, na Educação em Ciências, com o 
intuito de propiciar momentos de reflexão, observação e expressão a respeito daquilo que os sujeitos vivenciam, descobrem e constroem (MORAES e ANDRADE, 2009).

Dessa forma, é preciso compreender que o professor deve ter cuidado ao utilizar signos visuais, sendo requerida uma reflexão a seu respeito antes de leválos para sala de aula (GOUVÊA et al., 2016; SILVA, H. et al., 2006), para evitar interpretações distorcidas ou reducionistas de processos e/ou fenômenos científicos.

Isso perpassa a necessidade de instrumentalizar o professor para ler um signo visual e, por consequência, para que ele compreenda esse signo como uma estrutura análoga, ou seja, um modelo, repassando essa percepção para o estudante (GOUVÊA et al., 2016; SILVA, H. et al., 2006). Portanto, a leitura do signo visual estará intrinsecamente associada aos conhecimentos prévios dos sujeitos e ao seu conjunto de signos. Com isso, é essencial que o professor entenda a necessidade de estabelecer níveis corretos de leitura, o que pode ser feito pelo apoio de títulos, legendas e identificações dentro do signo visual, que agora tem o seu teor multimodal reforçado (ALBUQUERQUE, 2018). É em função disso que se compreende que todo signo visual é um elemento de um texto multimodal (ROSE, 2001; VAN LEEUWEN, 2008).

Na visão de Kress e van Leeuwen (2006) o letramento visual é axiomático para que os indivíduos compreendam os signos visuais aos quais são expostos. Contudo, este letramento precisa também ser multimodal, pois somente por meio do conhecimento do conjunto de signos que perpassa a construção de textos multimodais é que o leitor será capaz de compreendê-los criticamente e não apenas reproduzi-los. Silva et al. (2006) inserem esta compreensão no processo de trabalho com signos visuais na Educação em Ciências. Os autores destacam a importância de formar o olhar do docente no percurso, posto que "o professor tem papel indispensável na maneira como esses recursos podem mediar a produção de sentidos pelos estudantes. [...]. É importante que a formação inicial e continuada de professores leve em conta esse papel mediador do professor, pois ela é responsável pela sua constituição". (SILVA et al., 2006, p.220)

Albuquerque (2018) sugere a necessidade de uma formação que compreenda uma linguagem complexa, que não é mais contemplada pela linguagem verbal, mas que desenvolve interações com ela a partir de diversos modos semióticos - uma linguagem multimodal. Contudo, "a habilidade de produzir textos multimodais deste tipo, por mais importante que seja seu papel na sociedade contemporânea, não é ensinada nas escolas" (KRESS e VAN LEEUWEN, 2006, p.17, tradução do autor).

Além disso, desde a tenra idade, quando as crianças, em seu início de vida escolar, constroem signos visuais eles não são devidamente analisados pelos professores; a partir de um dado momento educacional, chegam a ser ignoradas no processo educativo (NOBLE e BESTLEY, 2016). Contudo, o signo visual, em nossa compreensão majoritariamente multimodal, continua a ter destaque na sociedade e a impactar naquilo que o estudante aprende e que o professor almeja ensinar.

No entendimento de Silva, H. et al. (2006) tudo que foi enaltecido anteriormente como necessário é geralmente dispensado nos cursos de formação de professores porque se estabelece uma relação automática com esses signos visuais.

Para Perales e Gimenez (2002) esse automatismo na forma dos professores lidarem com signos visuais prejudica a compreensão dos estudantes, basicamente, porque, na opinião dos autores, existem várias evidências - de cunho empírico 
e teórico - a respeito de uma distinção entre os "códigos gráficos" (p. 383) manipulados por estudantes e professores, criando um fosso entre eles durante a aula. Dessa forma, é imperativo atentar para estudos que trabalhem Textos Multimodais na Educação em Ciências, principalmente por considerar o desafio que a Multimodalidade acresce aos professores, que seria o desenvolvimento do seu próprio letramento visual, para assim conseguir apropriar-se do recurso multimodal na sua prática pedagógica cotidiana (PERREIRA e TERRAZAN, 2011).

GOUVÊA et al. (2016) sinalizam a carência de estudos que abordem a temática nos cursos de licenciatura, constituindo-se como uma lacuna que precisa ser preenchida com mais estudos acerca de Textos Multimodais em cursos superiores de formação de professores.

O estudo de Albuquerque (2018) corrobora esta ideia quando sugere a formação sobre Multimodalidade como ferramenta teórica e analítica que possibilita ao licenciando a manipulação de Textos Multimodais ligados ao conteúdo "Respiração humana", visando a facilitar o processo de ensino e aprendizagem.

Nesse viés, Kress e van Leeuwen (2006) propõem uma Gramática do Design Visual (GDV) que compreende três tipos de sujeitos envolvidos com um texto multimodal: a) produtor, que seria aquele responsável pela construção e encadeamento dos argumentos e, no caso da publicidade, das estratégias de convencimento; b) participante representativo, que se destaca por ser o ator representando papéis dentro do texto multimodal, cuja função é interagir com o seu receptor; e c) leitor interativo, que seria o sujeito que recebe a mensagem presente no texto multimodal à medida que com ela interage, interpreta-a e constrói um sentido ao seu entorno, sendo este o que necessita de um letramento multimodal.

O estudo de Albuquerque (2018) mostrou contribuições formativas importantes da GDV como ferramenta de instrumentalização para a multimodalidade, tais como: a autorreflexão dos professores sobre o emprego de signos visuais para a construção de slides com a temática "respiração pulmonar" e como a memória visual de sua formação impactou neste emprego; a percepção dos professores envolvidos no processo de que signos visuais devem ser escolhidos a partir do que se deseja ensinar, se um processo ou um conceito científico; a superação da memória visual desses professores, possibilitando a construção de novos recursos multimodais.

Dessa forma, a GDV de Kress e Van Leeuwen (2006) propõe-se a ser um aporte para análise e leitura de Textos Multimodais, possibilitando a compreensão do todo significante e, assim, propiciando aos sujeitos a compreensão do papel desse do ponto de vista social. Portanto, a GDV pode auxiliar na instrumentalização do professor da Educação em Ciências para ler e utilizar Textos Multimodais de campanhas sanitárias. Para tanto, é preciso compreender que esta abordagem possui três funções linguístico-semióticas simultâneas.

A primeira, denominada de Função Representacional, evoca os constituintes imagéticos de um texto multimodal como representações de algo (KRESS e VAN LEEUWEN, 2006). Ou seja, se temos a fotografia ou um desenho esquemático do díptera $A$. A egypti, tem-se apenas uma representação imagética do organismo, que pode ter suas cores e proporções naturais alteradas intencionalmente. Essa representação pode ser narrativa, quando se ocupa dos processos desencadeados no Texto Multimodal através de vetores explícitos 
(setas indicando sequência de processos) ou implícitos (olhar, gestos, caminhar e etc.); ou conceitual, que é objetiva, ocupando-se de conceitos e classificações que correlacionem um todo a uma parte (SEGATTO e KNOLL, 2013).

A segunda é chamada de Função Interativa e compreende que os três tipos sujeitos em interação constante (produtor, participante e leitor) são políticos e sociais (SANTOS e PIMENTA, 2014). Noutras palavras, o processo de produção, representação e leitura de um Texto Multimodal é dotado de intencionalidades, uma vez que tanto o produtor irá compor o texto e escolher os participantes representativos visando a objetivos, quanto o leitor irá construir sentido num âmbito político e social. Esse processo interativo pode ser de demanda (quando o participante representativo executa ações direcionadas ao leitor interativo) ou de oferta (quando não há participante representativo ou se este não dirirgir nenhuma ação ao leitor interativo). Além disso, é preciso observar o contato, que pode ser estabelecido a partir de um plano aberto (no qual aparecem os participantes representativos de corpo inteiro mais o ambiente em que se inserem, estabelecendo distância) ou fechado (havendo um close nos participantes representativos, em geral na linha dos ombros, que propõe proximidade e intimidade) (KRESS e VAN LEEUWEN, 2006).

Por último, a Função Composicional busca respaldar, segundo Kress e Van Leeuwen (2006), uma análise da forma como o Texto Multimodal é composto no sentido de atribuir valor informacional (informação conhecida localizada do lado esquerdo, o que é tido como novo é apresentado do lado direito, o que pertence ao mundo real na parte inferior e ideal a ser alcançado na região superior) que pode interferir, a partir dos significados desencadeados socialmente, no processo de construção particular de sentidos e, até, no caso de professores, na mediação de sentidos. Além disso, a saliência oferece destaque para elementos específicos na mensagem transmitida (SEGATTO e KNOLL; 2013); o enquadramento seria uma moldura que envolve um grupo de composições (pessoas, objetos, entre outros) (SANTOS e PIMENTA, 2014); e a modalidade pode ser classificada em naturalística, quando os padrões de cor se aproximam ao máximo do in natura, ou científica, que ocorre quando o produtor da imagem modifica os padrões de cores para oferecer maior detalhamento a uma parte da composição (KRESS e VAN LEEUWEN, 2006).

A partir disso, é possível indicar os objetivos desta pesquisa: analisar um impresso de combate a transmissão não vetorial do Zika vírus, que aqui será denominado de Texto Multimodal Publicitário e Sanitário (TMPS), com base na GDV; investigar o processo de construção de sentido por licenciandos em Ciências Biológicas sobre o TMPS escolhido como objeto de pesquisa; averiguar a GDV como ferramenta de instrumentalização do professor para alterar o TMPS, adequando-o ao ambiente educacional.

\section{METODOLOGIA}

Esta pesquisa pode ser entendida como de cunho qualitativo e colaborativo, visto que o desenvolvimento das atividades perpassou a necessidade de possibilitar a construção de espaços de autorreflexão para Licenciandos em Ciências Biológicas, usando o trabalho colaborativo como instrumento (IBIAPINA, 2016). 
A primeira parte desse estudo consistiu na análise, a partir das funções da GDV de Kress e Van Leeuwen (2006) (Representacional, Interativa e Composicional), de um TMPS (fig. 1) que foi veiculado, em 2016, pelo Ministério da Saúde (MS) brasileiro como parte da campanha "\#MosquitoNão", 1 tratando da transmissão não vetorial do Zika vírus.

\section{Figura 1. TMPS da campanha "\#MosquitoNão" que trata da transmissão não vetorial do Zika vírus}

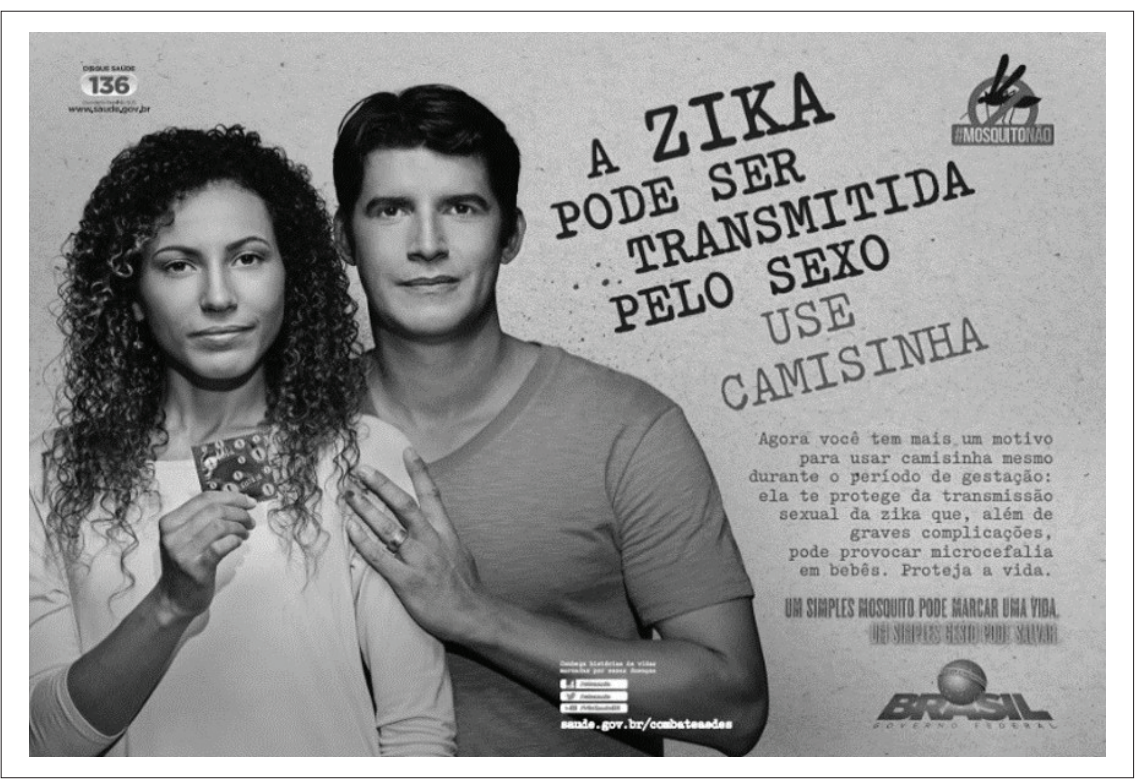

Fonte: Original, em cores, disponível em: http://portalarquivos2.saude.gov.br/images/jpg/2016/dezembro/15/combate-0a-mosquitocartaztransmissao-sexual-64x46a.jpg

A segunda parte da pesquisa consistiu na apresentação do TMPS (fig. 1) a um grupo de doze Licenciandos em Ciências Biológicas, matriculados em uma Universidade Federal brasileira. É importante salientar que este artigo é um recorte de um processo formativo desenvolvido em uma disciplina eletiva de graduação que contava com quarenta e dois estudantes matriculados. A pesquisa envolveu a análise de quatro TMPS distintos pertencentes a campanha "\#MosquitoNão", trazendo uma enorme quantidade de dados. Dessa forma, optou-se por escolher, como recorte para o presente artigo, apenas os doze estudantes que analisaram o TMPS objeto da transmissão não vetorial do Zika vírus.

Além disso, confeccionou-se, a partir de legislação oficial, um Termo de Consentimento Livre e Esclarecido (TCLE) para ser assinado, em duas vias, por todos os licenciandos que concordaram em participar do estudo no primeiro dia de aula da disciplina eletiva. Os estudantes que não assinaram o TCLE não participaram do estudo.

Após a assinatura do TCLE, os doze estudantes agruparam-se, de acordo com as suas afinidades, em dois Grupos de Trabalho (GT A e GT B) com seis componentes cada. Este agrupamento atende um pressuposto da pesquisa colaborativa de Ibiapina (2016), que pressupõe o desenvolvimento de atividades em colaboração. 
Cada GT recebeu um protocolo contendo as seguintes perguntas abertas: I) Qual a principal mensagem da propaganda?; II) Qual a relação estabelecida entre imagem e texto verbal?; e III) Existe algum tipo de limitação nesta propaganda?. Esse questionário prévio possibilitou que os licenciandos expressassem suas impressões iniciais sobre o TMPS, possibilitando uma leitura sobre a compreensão deles, antes da formação sobre a GDV, a respeito da mensagem principal do TMPS, da relação entre verbal e não-verbal no TMPS e sobre possíveis limitações dentro do Texto Multimodal. A análise dessas percepções prévias possibilitou entender como a formação sobre a GDV impactou no processo de construção de sentido dos licenciandos.

Após responder as questões prévias, os estudantes foram submetidos a um curso com 20 horas/aula de duração sobre a GDV. A formação foi dividida em duas partes: I) teórica, que consistiu no estudo dos elementos teóricos relacionados as funções da GDV e as demandas atuais para a formação de professores de Ciências Biológicas; e II) prática, sendo constituída pela análise conjunta de Textos Multimodais relacionados às Ciências Biológicas e não ligados ao combate de qualquer arbovirose, evitando que isso pudesse impactar as próximas etapas da pesquisa.

A divisão do curso formativo foi necessária em função da orientação da Semiótica Social, base da GDV e da Multimodalidade, para que sejam considerados o contexto social de leitura dos sujeitos (HODGE e KRESS, 1988; VAN LEEUWEN, 2008). Portanto, foi imprescindível levar em conta elementos que discutissem as demandas formativas para professores de Biologia, considerando o contexto dos sujeitos para escolha dos Textos Multimodais que compuseram a parte prática do curso.

Com o fim do processo de formação os licenciandos formaram novamente os GT, com a mesma configuração inicial, tendo sido submetidos a duas orientações: I) analise a propaganda (fig. 1) a partir da GDV e II) proponham alterações que possam melhorar o material (fig. 1) para uso em sala de aula.

$\mathrm{Na}$ análise foram considerados os pressupostos da GDV (KRESS e VAN LEEUWEN, 2006), levando em conta quais elementos da teoria foram mobilizados pelos GT antes e após a formação; se e como os estudantes propuseram superar as dificuldades encontradas nas propostas de alterações dos GT; aspectos relacionados a Educação em Saúde que poderiam encontrar-se presentes tanto no TMPS como nos dados coletados com os licenciandos (Culpabilização da vítima; lógica puramente transmissional, mecanismos de diálogo, dentre outros) de acordo com alguns autores (FALKENBERG et al., 2014; FREITAS e REZENDE-FILHO, 2011; VALLA, 2006; VASCONCELOS, 2015).

Além disso, foram levados em conta elementos que podem ter sido modificados/mantidos nas considerações dos GT sobre o TMPS antes e após a formação sobre a GDV, considerando as respostas ao questionário prévio, as atividades desenvolvidas ao fim da pesquisa e resgatando elementos da análise do TMPS.

\section{RESULTADOS E DISCUSSÕES}

\section{Análise semiótica do TMPS}

O TMPS analisado (fig. 1) é constituído por dois participantes representativos (um homem e uma mulher), que dirigem seus olhares para o leitor interativo, e, por esta 
razão, pode ser classificado como representacional narrativo não-transacional, tendo em vista a construção de uma linha vetorial por meio do olhar sem mostrar o destino da ação. Além disso, há outros dois processos executados: I) a participante do sexo feminino segura um preservativo masculino num gesto de mostrar algo para alguém (o leitor interativo); e II) o participante do sexo masculino posiciona uma de suas mãos no braço da participante feminina, enquanto coloca parte de seu corpo atrás do corpo dela, dando a entender que está executando um ato de proteção.

No que concerne à função interativa, o fato de os participantes representativos olharem diretamente para o leitor interativo e, um deles (participante do sexo feminino), executar uma ação direcionada ao leitor interativo (levantar a camisinha) nos permite o entendimento do TMPS (fig. 1) como de demanda, uma vez que o contato entre participantes e leitor exige a execução de uma ação (utilização de camisinha).

Ao observamos os textos verbais no TMPS é possível identificar os mesmos processos de direcionamento da mensagem, quase em tom de ordem ao leitor interativo, conforme os destaques em negrito a seguir: "Agora você tem mais um motivo para usar camisinha [...] Proteja a vida " e "Use camisinha". Dessa forma, há uma demanda de ações do leitor interativo - "usar camisinha" para "proteger a vida" - sendo estabelecida, pelo sujeito produtor do TMPS, uma sinonímia entre proteger a vida e valer-se do preservativo.

Além disso, há uma construção de sequência contínua entre recursos verbais e visuais, que nos leva à compreensão de um processo de narratividade, estabelecendo uma contiguidade multimodal, pois, à medida que se escolhe um mesmo padrão cor, modificando apenas a saturação, para os textos verbais "Use camisinha" e "Agora você tem mais um motivo [...]. Proteja a vida", há um processo sendo desencadeado, que relaciona o uso do preservativo a um motivo, construindo um argumento visual a partir dos níveis de saturação do texto verbal. Esses dados reforçam a tonalidade multimodal deste TMPS, avigorando a importância de proceder a uma análise em que os diversos modos semióticos sejam considerados (ROSE, 2001; VAN LEEUWEN, 2008).

Em termos de distância social o TMPS (fig. 1) se encontra no plano médio, tendo em vista que os participantes representativos não estão tão próximos do leitor interativo ao ponto de poder tocá-los; nem tão distantes ao ponto de não haver nenhum estabelecimento de contato, considerando que o plano não é aberto ao ponto de mostrar seus corpos inteiros, conforme determina a GDV de Kress e Van Leeuwen (2006). Dessa forma, o corte na linha da cintura estabelece uma proximidade mediana, induzindo o leitor interativo a pensar que os participantes da imagem lhe são relativamente íntimos.

Os ângulos horizontal e vertical são, respectivamente, frontal e nivelado. Isso se justifica em função do contato direto na linha dos olhos entre participantes e leitor, o que reforça o TMPS como de demanda, assim como estabelece uma proximidade muito grande entre eles, havendo de fato uma interação, um estabelecimento de diálogo imaginário.

Em termos de função composicional é possível entender que o TMPS possui enquadramento conectado, tendo em vista que tanto os participantes representativos como os textos verbais parecem estar imersos num mesmo espaço, 
sem haver uma limitação que os separa. Segundo Santos e Pimenta (2014) a ausência de molduras sugere que não há uma sequência para compreensão das informações, indicando que a mensagem do material só fará sentido se este for lido no todo. Dessa forma, é possível compreender que o TMPS analisado só terá significado se for considerado por completo, tanto os elementos verbais como os visuais.

A saliência pode ser observada no destaque para o preservativo masculino, dado o contraste estabelecido entre o lilás da sua embalagem e os demais elementos do TMPS, o que condiz com o destaque, em fonte maior, para os dizeres "A Zika pode ser transmitida pelo sexo" e em coloração diferente na frase "Use camisinha". É possível notar que as informações visuais e textuais se coadunam no sentido de coerseduzir o leitor interativo para a utilização do preservativo masculino. Tudo isso sugere que a utilização do preservativo masculino é a parte da mensagem que deve "saltar aos olhos" do leitor interativo.

É também possível identificar elementos classificados numa modalidade naturalística, de acordo com a GDV de Kress e van Leeuwen (2006), tendo em vista que há representações presentes na imagem na forma in natura - notadamente um homem, uma mulher e um preservativo masculino. Contudo, existem também elementos que podem ser classificados numa modalidade científica (o mosquito representado na logomarca da campanha e a representação do que parece ser o globo terrestre na logomarca do Governo Federal). Os resultados sugerem a opção pela modalidade in natura para representar elementos centrais da mensagem que o TMPS quer passar. Esse dado fortalece o processo de identificação do leitor interativo com os participantes representativos e a mensagem veiculada, terminando por atuar como marcadores de modalidade (HODGE e KRESS, 1988).

Ao analisarmos o TMPS com base no valor da informação veiculada em um texto multimodal, a partir das considerações de Kress e van Leeuwen (2006), é possível obter a figura 2, na qual observamos as repartições entre o que é considerado dado, novo, ideal e real na perspectiva da GDV. Conforme se observa (fig. 2) os elementos dados (lado esquerdo) são justamente as expressões faciais dos participantes representativos e o objeto camisinha, que um deles segura, ficando os elementos que tratam do combate a Zika como elementos novos (lado direito).

No plano ideal/real é possível identificar o preservativo masculino e os signos verbais que tratam dos modos de transmissão, já no plano real observa-se as possíveis complicações da Zika. A expressão de desconforto dos participantes representativos e a necessidade de utilizar camisinha foram colocadas no plano ideal. Regressando ao contexto brasileiro, as escolhas sígnicas se justificam levando em conta que a existência do preservativo e as complicações ocasionadas pelo Zika vírus são reais, elas existem de fato. Contudo, a utilização da camisinha a contragosto, conforme as expressões faciais dos participantes, parece ser uma das informações ideais e dadas. Ou seja, o TMPS não só naturaliza o incômodo no uso do preservativo como o coloca no status de ideal a ser alcançado.

Do ponto de vista de uma Educação em Ciências para a Saúde esses dados podem ser preocupantes, posto que, conforme coloca Almeida-Júnior (2000), a imagem como artefato deve ser considerada como veículo de informação e atua como modelo instituinte de realidades. Dessa forma, normalizar o incômodo na utilização do preservativo masculino abre margem para o seu não emprego frequente não contribuindo, portanto, para o processo de sensibilização sobre a importância do uso. 
Figura 2. TMPS demarcado com linhas pretas, indicando: 0 que é dado (lado esquerdo), novo (lado direito), real (parte inferior) e ideal (parte superior), conforme as etiquetas verbais

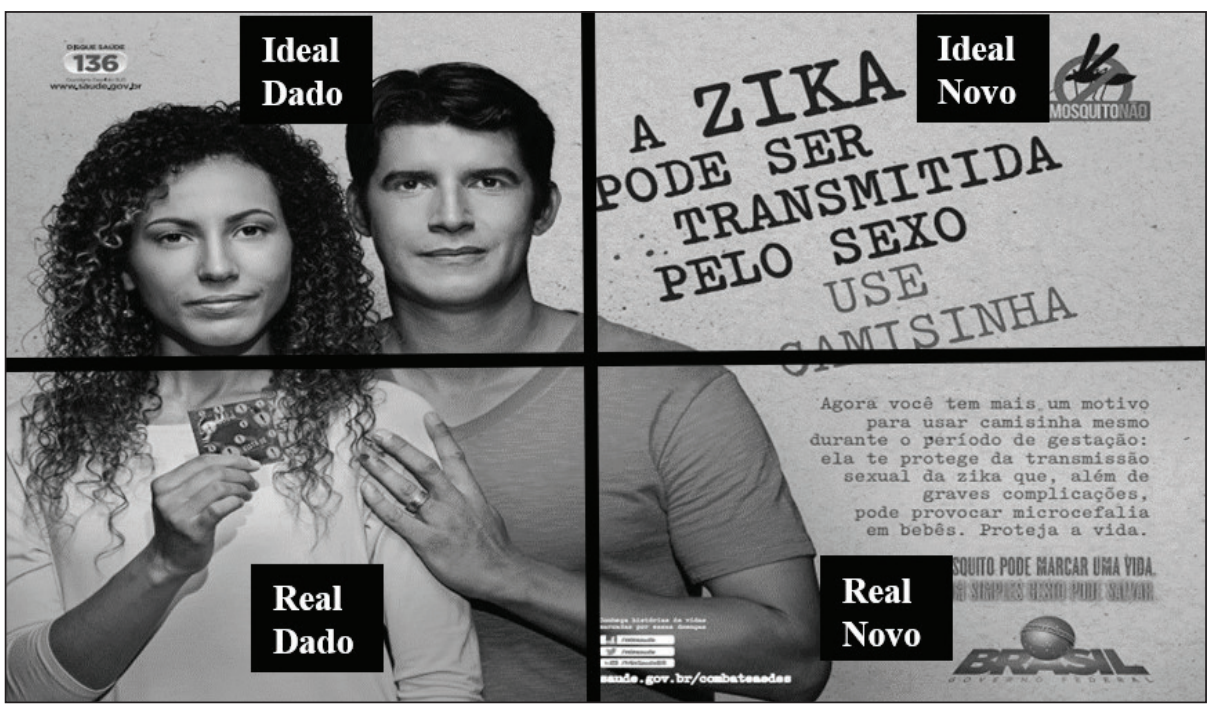

Fonte: Elaborado a partir de http://portalarquivos2.saude.gov.br/images/jpg/2016/dezembro/15/Combate-0a-MosquitoCARTAZ-TRANSMISSAOSEXUAL-64x46a.jpg.

Dito isto, o professor que irá atuar na sensibilização, utilizando este TMPS como objeto de mediação, precisa estar ciente da importância dessa análise prévia, assim como compreender a necessidade de ampliar e (re)construir os sentidos propagados, conforme Silva et al. (2006) destacam como essencial. Tudo isso para atender o propósito de uma Educação em Ciência para a Saúde que vise ao cuidado não pelo medo, mas sim pelo esclarecimento da necessidade.

\section{Respostas dos licenciandos ao questionário prévio}

No tocante à primeira questão (qual a principal mensagem dessa propaganda?), ambos os GT (A e B) afirmaram que o TMPS chama a atenção para a utilização do preservativo com a finalidade de evitar a transmissão da Zika. Ademais, o GT A entendeu que a mensagem principal deste TMPS seria que "a Zika tornou-se (sic) a mais recente Doença Sexualmente Transmissível". ${ }^{2}$

As leituras de ambos dos GT, notadamente do GT A, reforçam a compreensão da Zika como IST, assim como contextualizaram o TMPS à medida que houve a compreensão de um elemento novo no Texto Multimodal (KRESS e VAN LEEUWEN, 2006), que condiz com os estudos recentes sobre a possibilidade de transmissão sexual do Zika vírus (D’ORTENZIO, 2016; FOY et al., 2011; MUSSO et al., 2015). A partir disso, há também o entendimento de um elemento dado, que, segundo a GDV (KRESS e VAN LEEUWEN, 2006), são informações tidas como já conhecidas pelo leitor interativo ao qual o Texto Multimodal se destina. Neste caso, destaca-se a utilização do preservativo masculino, uma vez que sua utilização para prevenção de outras IST já é amplamente difundida no Brasil, havendo, inclusive, Texto Multimodais específicos para esta finalidade (ROCHA e FELTES, 2016). 
Outro aspecto destacado, especialmente pelo GT B, é a identificação da propagação de uma atitude (utilizar camisinha) não só para evitar a aquisição da Zika, como também a microcefalia em recém-nascidos, ambas as doenças seriam prejudiciais à saúde da população. Essas interpretações edificam o entendimento do TMPS como de demanda (KRESS e VAN LEEUWEN, 2006), à medida que compreendem que o Texto Multimodal solicita a execução de uma ação ao leitor interativo (uso de camisinha). Nesta direção, este TMPS pode ser compreendido como modelo instituinte de realidades (ALMEIDA-JÚNIOR, 2000), considerando que a ideia parece ser, por intermédio do material, dissuadir o leitor interativo de uma conduta prejudicial à coletividade (CHARAUDEAU, 2013), que neste caso seria a não utilização do preservativo masculino.

Em termos da relação imagem/texto verbal (segunda questão) o GT A afirmou que enquanto a imagem evidencia o método de prevenção, cabe ao texto verbal somente complementar seu conteúdo com outras informações. Entretanto, para o GT B tanto imagem como texto verbal se coadunam em seus significados, transmitindo a mesma mensagem de formas distintas.

O GT A evidenciou um tipo de relação imagem/texto verbal no qual a primeira é o elemento central e ao segundo cabe o complemento. Na perspectiva de Albuquerque (2018) é preciso compreender estes elementos como complementares entre si, integrantes da mesma mensagem. Esta leitura ratifica a intencionalidade que provavelmente se encontra por trás do destaque oferecido ao preservativo masculino, endossando a mensagem verbalizada e construindo o todo significante da mensagem.

Kress e van Leeuwen (2006), ao proporem a GDV com base nos pressupostos da multimodalidade, entenderam a relação entre visual e verbal como um processo de interação para formar um todo significante. O GT B demonstrou uma compreensão multimodal do TMPS, sinalizando que os elementos semióticos presentes (especificamente escritos e imagéticos) atuam como linguagens e, portanto, transmissores de mensagens de forma independente.

A última questão (Existe algum tipo de limitação nesta propaganda?) indicou que para o GT A o problema essencial se concentra no fato do $A$. aegypti, como principal vetor da doença em território brasileiro, ficar em segundo plano, carecendo, portanto, de maior atenção neste TMPS. Para o GT B há um "preconceito com relação ao sexo feminino”, uma vez que atribui à mulher a responsabilidade pela transmissão da Zika no ato sexual. O grupo afirma que essa compreensão é possível quando se considera que apenas a representante interativa do sexo feminino segura o preservativo, cabendo ao homem o papel de "acompanhante", quando ambos deveriam estar em pé de igualdade, inclusive segurando cada um o seu preservativo.

Os GT elencaram duas problemáticas. Primeiro, a indicada pelo GT A refaz a discussão em torno da importância de analisar o material que é levado para a sala de aula durante o processo de Educação em Ciências para a Saúde, o que reforça a necessidade de letrar multimodalmente professores em formação inicial para que estes compreendam a importância pedagógica da análise, conforme já destacaram Noble e Bestley (2016). Tudo isso possibilita entender que os conteúdos biológicos contidos nas mídias carecem de complementações.

Em segundo lugar, a situação destacada pelo GT B fortalece a importância de se tentar identificar as ideologias por trás dos processos de escolha sígnicas, sobretudo 
considerando o contexto social de produção e veiculação (SANTOS e PIMENTA, 2014). Dessa forma, quando o GT B salienta que o fato do preservativo ser segurado pela mulher, enquanto o homem atua como acompanhante, pode significar que o material endossa uma concepção machista presente na sociedade brasileira em torno da transmissão das IST: cabe à mulher preocupar-se com sua proteção, eximindo o homem de responsabilidade. Esse processo pode indicar a existência de "culpabilização da vítima" (VALLA, 2006), ou de uma das vítimas (a mulher), no TMPS.

Dessa forma, compreender essas nuances pode possibilitar a ampliação do processo de transmissão sexual do Zika vírus, construindo um espaço de debate que leve ao entendimento de que a proteção é papel de ambos os sujeitos envolvidos na relação sexual, ocorrendo um processo de sensibilização do homem, para com sua parcela de responsabilidade, e desculpabilização da mulher, que é uma vítima.

\section{Análise dos licenciandos após a formação sobre a GDV}

Ambos os GT (A e B) levaram em conta elementos da GDV e da Educação em Ciências para Saúde (quadro1), assim como nota-se que ambos mencionaram, em alguns momentos, elementos do TMPS que viessem a justificar as afirmações realizadas na análise. Alguns exemplos dessa menção podem ser encontrados quando o GT A cita a função interacional de oferta/demanda; e quando o GT B justifica porque o TMPS é desconectado e pertencente à função narrativa (quadro 1).

Esses dados podem sinalizar uma compreensão dos GT de que o processo analítico, a partir da GDV, requer uma justificação dos elementos encontrados tanto do ponto de vista da teoria como da perspectiva do material analisado.

Ainda assim, essa compreensão parece ser em caráter propedêutico e restrito a alguns elementos do TMPS, posto que é possível evidenciar no quadro 1 diversas menções aos conhecimentos da GDV sem proceder a sua explicação ou justificação. Alguns exemplos disso são: quando o GT A apenas menciona uma distância social de plano médio, uma atitude horizontal e vertical nivelada e a modalidade naturalística; e quando GT B segue a mesma linha ao apenas citar a modalidade naturalística, assim como determinar que o TMPS possui um ângulo horizontal frontal e vertical nivelado.

Outro aspecto das análises a ser salientado é que ambos os GT afirmaram, no tocante à função interacional, que o TMPS estabelece relações de oferta e de demanda de forma simultânea entre o casal ali representado (participantes representativos) e o sujeito que recebe a mensagem (leitor interativo). Segundo as análises dos grupos (quadro 1) o casal mostra/oferta o preservativo masculino para o leitor interativo ao tempo que solicita seu uso para evitar a Zika.

Kress e van Leeuwen (2006) atentam que uma imagem será sempre exclusivamente de oferta ou exclusivamente de demanda, sinalizando que a afirmação dos licenciandos não procede. Os autores destacam que uma imagem de oferta possui apenas elementos visuais soltos, que são, em geral, objetos ou representações não antropomórficas; já uma imagem de demanda possui sujeitos humanos ou humanizados em interação direta ou indireta com o leitor interativo.

Dessa forma, o ato de "oferta do preservativo", utilizado como justificativa para classificar o TMPS como de oferta não procede, uma vez que o uso da camisinha masculina já é amplamente conhecido para evitar a infecção com outras 
IST no Brasil (ROCHA e FELTES, 2016), não se tratando de um objeto não antropomórfico ofertado em desconexo, mas sim tendo seu uso solicitado para evitar a infecção com o Zika vírus, conforme os estudos de Foy et al. (2011).

Quadro 1. Análises dos GT C1 e C2 ao TMPS C com destaque para os conhecimentos mobilizados relacionados a GDV e a Educação em Ciências para Saúde.

\begin{tabular}{|c|c|c|}
\hline GT & RESPOSTAS NA ÍNTEGRA & OBSERVAC̣ÕES \\
\hline C1 & $\begin{array}{l}\text { Interacional com contato de demanda, distância } \\
\text { social de plano médio, atitude horizontal frontal e } \\
\text { vertical nivelado. } \\
\text { Composicional de valor informacional existente/ } \\
\text { novo e modalidade naturalística } \\
\text { [...] o [elemento] que mais teve predominância foi o } \\
\text { interacional, por se tratar de uma propaganda que } \\
\text { passa oferta (camisinha para prevenir a Zikal e exige } \\
\text { demanda (uso da camisinha para evitar a Zika). }\end{array}$ & $\begin{array}{l}\text { Mobilização de } \\
\text { conhecimentos sobre as } \\
\text { funções da GDV }\end{array}$ \\
\hline C2 & $\begin{array}{l}\text { [...] é interacional, pois estabelece um contato com } \\
\text { o leitor através do olhar dos personagens e do texto } \\
\text { [...] que estabelecem uma demanda. Além disso, a } \\
\text { distância social presente na imagem é de um plano } \\
\text { fechado e possui um ângulo horizontal frontal e } \\
\text { vertical nivelado. Ademais, a imagem também } \\
\text { apresenta outras funções, como por exemplo a } \\
\text { função narrativa, pois os personagens (casal) } \\
\text { estabelecem uma ação com os vetores implícitos } \\
\text { através da direção do olhar e o modo como a mulher } \\
\text { segura a camisinha, mostrando pro leitor que deve } \\
\text { usar, [...] e também a função composicional, visto } \\
\text { que a modalidade da imagem é naturalística e a } \\
\text { saliência está perceptível no casal, tendo em vista } \\
\text { que o enquadramento da imagem é desconectado } \\
\text { porque não há uma conexão entre os elementos } \\
\text { verbais e não-verbais através de setas. }\end{array}$ & $\begin{array}{l}\frac{\frac{\text { Mobilizacão de }}{\text { conhecimentos ligados }}}{\text { a Educacão em Ciências }} \\
\text { para a Saúde }\end{array}$ \\
\hline
\end{tabular}

Fonte: Dados da pesquisa, 2019.

Ao resgatarmos as interpretações prévias é possível constatar que o GT A já sinalizava a compreensão de que a transmissão sexual da Zika era um elemento novo no TMPS, sendo requerida a utilização do preservativo ao leitor interativo. O GT B também entendeu que o TMPS demandava algo. Dessa forma, é possível que a introdução da GDV tenha contribuído para a confusão no processo de atribuição de sentido desses GT, destacando a necessidade de maiores estudos e formações a este respeito.

Uma compreensão interessante, destacada pelo GT B, é o entendimento do TMPS como representacional narrativo, utilizando como subsídios para esta compreensão: o gesto de "segurar a camisinha"; o olhar direcionado ao leitor interativo; e "a forma como o homem toca o ombro da mulher" (quadro 1). Isso mostra que esse GT compreendeu que os vetores podem ser explícitos e/ou implícitos (KRESS e VAN LEEUWEN), demonstrando a importância de nossa 
formação para que eles distinguissem imagens narrativas de conceituais, podendo ser capazes de utilizá-las corretamente, uma vez que ambos os tipos são essenciais na Educação em Ciências e, por consequência, na Educação em Ciências para a Saúde.

Além disso, o GT B entende o TMPS como desconectado, uma vez que, segundo o grupo, não há conectivos entre os componentes do texto multimodal. Todavia, é importante frisar que a utilização de conectivos só é necessária quando há diversos quadros compondo e separando o todo do texto em partes (SEGATTO e KNOLL, 2013). Essa separação não é visualizável no TMPS uma vez que o fundo aplicado a todos os elementos é o mesmo, sem haver nenhum enquadre envolvendo os grupamentos de elementos, conforme já demonstramos na análise inicial. Dessa forma, o entendimento do GT B pode significar a não compreensão de detalhes a respeito deste elemento da GDV.

\section{As propostas de alterações dos licenciandos ao TMPS}

É possível notar que ambos os GT questionaram a legibilidade de itens do TMPS, sugerindo um aumento de fontes textuais dos meios de contato especializados (GT A, quadro 2) ou da figura do mosquito (GT B, quadro 2).

O tamanho de fontes textuais ou de imagens num Texto Multimodal, na perspectiva da GDV, é uma das formas de conferir saliência a determinadas informações (KRESS e VAN LEEUWEN, 2006). Dessa forma, ao sinalizarem a necessidade de um aumento, quer seja de recursos verbais ou visuais, os GT utilizaram conceitos da GDV explicados durante o processo formativo.

Nessa perspectiva, quando o GT A sugeriu que os contatos especializados (disque saúde, redes sociais da campanha, dentre outros) deveriam ter uma fonte maior há o entendimento de que esses veículos de comunicação com a população deveriam ter mais saliência no TMPS. A afirmação deste GT faz sentido, sobretudo se partirmos do entendimento de que esses veículos podem significar um feedback da população, incluindo professores da Educação em Ciências para a Saúde, que podem impactar na confecção dos próximos materiais pelo MS e desembocando em um processo de participação popular na questão nos moldes trazidos por Falkenberg et al. (2014) e Vasconcelos (2015).

É importante destacar que nas interpretações prévias o GT A não atentou para a rede de contatos, o que pode sinalizar que o processo formativo pode ter contribuído para a construção de um olhar analítico, impactando positivamente no processo de construção de sentido do grupo.

Em paralelo, ao sugerir um aumento da imagem do mosquito no TMPS, o GT B parece entender que o vetor biológico da doença merece mais destaque. O entendimento do grupo é compreensível porque o comportamento hematófago da fêmea do $A$. aegypti infectada ainda é o principal mecanismo de transmissão do Zika vírus (D’ORTENZIO et al., 2016). Contudo, a sugestão de alteração do grupo sinaliza, mais uma vez, a importância pedagógica da análise prévia desse e de qualquer outro Texto Multimodal, pois não se pode esquecer que este é um elemento de toda uma campanha (\#MosquitoNão) e sua análise prévia possibilita ao professor escolher elementos dela que se complementem. 
Quadro 2. Propostas de adaptações dos GT C1 e C2 ao TMPS C com destaque para os conhecimentos mobilizados relacionados a GDV e a Educação em Ciências para Saúde

\begin{tabular}{|c|c|c|}
\hline GT & RESPOSTAS NA ÍNTEGRA & OBSERVAC̣ÕES \\
\hline C1 & $\begin{array}{l}\text { Ampliar fonte dos meios de contato } \\
\text { especializados, os dois participantes segurarem } \\
\text { cada um a (sic) sua camisinha, aumentar a fonte } \\
\text { dos meios de prevenção. }\end{array}$ & $\begin{array}{l}\text { Mobilização de } \\
\text { conhecimentos sobre as } \\
\text { funções da GDV }\end{array}$ \\
\hline C2 & $\begin{array}{l}\text { Para melhorar a imagem é necessário que haja } \\
\text { a ampliação da figura do mosquito, pois se } \\
\text { não houver essa ampliação o leitor talvez não } \\
\text { estabelecerá a relação de que o mosquito é o fator } \\
\text { crucial para a transmissão do Zika Vírus por meio } \\
\underline{\text { da relação sexual. Outro fator importante é inserir o }} \\
\text { ciclo de vida do mosquito e as formas de prevencão. }\end{array}$ & $\begin{array}{l}\frac{\text { Mobilizacão de }}{\text { conhecimentos ligados }} \\
\text { a Educação em Ciências } \\
\text { para a Saúde }\end{array}$ \\
\hline
\end{tabular}

Fonte: Dados da pesquisa, 2019.

Outra sugestão do GT A é que "os dois participantes [deveriam] segurar cada um a (sic) sua camisinha" (quadro 2). A colocação do GT A reforça a importância de instrumentalizar os professores para leitura, análise e adaptações de Textos Multimodais, pois assim eles podem perceber que todo o processo de construção multimodal não é arbitrário, mas sim intencional e, portanto, propaga ideologias políticas e sociais (SANTOS e PIMENTA, 2014).

Nesse sentido, os professores da Educação em Ciências para a Saúde, quando instrumentalizados com a GDV, poderão atentar-se para as nuances de Textos Multimodais de campanhas sanitárias levados para o ambiente da sala de aula, podendo identificar, discutir possíveis questões ideológicas com os estudantes e, assim, contribuindo para a autonomia crítica do sujeito, que seria o principal objetivo da Educação Popular em Saúde (FALKENBERG et al., 2014; VALLA, 2006), que subsidia a nossa Educação em Ciências para a Saúde.

\section{CONSIDERACִÕES FINAIS}

Ao longo desse estudo, foi possível refletir a respeito da necessidade de pensar impressos de campanhas sanitárias como instrumentos de mediação de conhecimentos, sinalizando a necessidade de promover um letramento multimodal de professores.

Nesse sentido, o processo de análise prévia começou a oferecer indícios sobre a importância de preparar o professor para escolher e pensar sobre as mensagens veiculadas neste TMPS e em outros impressos de campanhas sanitárias. Isso evidenciou o papel do professor como mediador para a aplicação desse tipo material, uma vez que cabe a ele refletir com os estudantes até que ponto as medidas demandadas contribuem para o combate a transmissão não vetorial da Zika. Ou seja, estudos com esse tipo de material podem oportunizar um espaço para uma Educação em Ciências para a Saúde numa perspectiva de oferecer autonomia aos sujeitos educandos, o que abre margem para novas pesquisas nessa direção. 
Ao procedermos uma discussão sobre as principais distinções entre as interpretações prévias de cada GT com aquelas posteriores à formação ministrada é possível verificar como a GDV subsidiou as construções de sentido de Licenciandos em Ciências Biológicas sobre o TMPS. Nesse sentido, os GT sinalizaram, após a formação sobre a GDV, a construção de um olhar mais crítico em relação as suas interpretações prévias. Esse dado fortalece a ideia de que análise de todo Texto Multimodal se constitui como um importante recurso pedagógico, mas, antes disso, esta análise precisa ter um respaldo teórico e analítico, o que sinaliza a contribuição da GDV nesse sentido.

Esses aspectos demonstram que o processo de construção de sentido foi diretamente impactado pela formação sobre a GDV, uma vez que ela possibilitou aos licenciandos ferramentas para analisar os TMPS e, por consequência, compreender esses recursos como instrumentos de mediação de conhecimentos e não apenas como um conjunto de informações a serem absorvidas.

Dessa forma, há endosso sobre a necessidade dos cursos de formação abordarem questões relacionadas à Multimodalidade. Isso fica evidente porque, apesar dos apontamentos positivos, dificuldades podem ser elencadas no decorrer da análise, tais como: compreensão de que o TMPS poderia ser classificado como oferta e demanda simultaneamente, coisa que contraria a GDV; e o entendimento das funções da GDV como categorias.

Contudo, é importante salientar que essa formação foi o primeiro contato dos licenciandos com a GDV e a Multimodalidade, o que talvez justifique as dificuldades. Além disso, consideramos a duração do curso e a falta de atividades individualizadas como dois possíveis fatores agravantes. Com isso, os dados parecem reforçar duas necessidades: 1) pensar os próximos cursos de formação sobre a GDV atentando para essas dificuldades; e 2) promover cursos mais longos, reconhecendo a necessidade de mesclar atividades individuais àquelas desenvolvidas em grupo.

Nesse sentido, a presente pesquisa constitui-se como percussora para outros tantos estudos futuros, contribuindo com reflexões acerca da importância de letrar os professores multimodalmente para lidar com campanhas sanitárias, estabelecendo a GDV como uma ferramenta teórica e analítica para pensar essas campanhas de forma crítica, à medida que as entendemos como recursos pedagógicos em potencial.

\section{REFERÊNCIAS}

ALBUQUERQUE, T. C. C. de. Uma imagem vale mais com mil palavras: estudo sobre a produção de textos multimodais para o ensino do conceito de respiração pulmonar. 2018. 186 f. Tese (Doutorado Ensino das Ciências e Matemática) - Universidade Federal Rural de Pernambuco. Departamento de Educação, Pernambuco, Recife, 2018.

ALMEIDA JÚNIOR, J. B. de. Alfabetização para leitura de imagens: apontamentos para uma pesquisa educacional, Revista de Educação da PUC-Campinas, n.8, p. 15-21, jun. 2000.

ATKINSON, B. et al. Detection of zika virus in semen. Emerg Infect Dis, v. 22, n.5, p.940, 2016.

BIZZO, N. Mais ciência no ensino fundamental: metodologia do ensino em foco. São Paulo: Editora do Brasil, 2009. 
CHARAUDEAU, P. Imagem, mídia e política: construção, efeitos de sentido, dramatização, ética. In.: MENDES, E (Coord.); MACHADO, I. L.; LIMA. H.; LYSARDO-DIAS, D. (Org.). Imagem e discurso. Belo Horizonte: FALE-UFMG, 2013. p. 383-405.

D’ORTENZIO, E. et al. Evidence of Sexual Transmission of Zika Virus. N Eng1 J Med, v. 374, n. 22, p. 2195-8, jun. 2016.

FALKENBERG, M. B. et al. Educação em saúde e educação na saúde: conceitos e implicações para a saúde coletiva. Ciência \& Saúde Coletiva, v. 19, n. 3, p. 847-852, 2014.

FOY, B. et al. Probable Non-Vector-borne Transmission of Zika Virus, Colorado, USA. Emerg Infect Dis, v. 17, n. 5, p. 880-882, 2011.

FREITAS, F. V. de; REZENDE FILHO, L. A. Modelos de comunicação e uso de impressos na educação em saúde: uma pesquisa bibliográfica. Interface - Comunicação, Saúde, Educação, v.15, n. 36, p. 243-55, jan./mar. 2011.

GOUVÊA, G. et al. Modos de ler imagens em contextos de formação inicial de professores. Revista Educação e Cultura Contemporânea, v. 13, n. 31, p. 135-159, 2016.

HODGE, R.; KRESS, G. Social Semiotics. Cambridge: Polity Press, 1988.

IBIAPINA, I. M. L. de M. Reflexão sobre a produção do campo teórico-metodológico das pesquisas colaborativas: gênese e expansão. In.: IBIAPINA, I. M. L. de M.; BANDEIRA, H. M. M.; ARAÚJO, F. A. M. (Org.). Pesquisa colaborativa: multirreferenciais e práticas convergentes - 2016.

KRESS, G.; VAN LEWEEN, T. Reading images: the grammar of visual design. London, New York: Routledge, 2006.

MORAES, M. B.; ANDRADE, M. H. de P. Ciências: ensinar e aprender. Belo Horizonte: Dimensões, 2009.

MUSSO, D. et al. Potential Sexual Transmission of Zika Virus. Emerging Infectious Diseases, v. 21, n. 2, p. 359-361, 2015.

NOBLE, I.; BESTLEY, R. Visual research: an introduction to research methodologies in graphic design. $3^{\mathrm{a}}$ ed. London: Fairchild Books, 2016.

PUCCIONI-SOHLER, Marzia et al. Dengue infection in the nevorus system: lessons learned for Zika and Chikungunya. Arq. Neuro psiquiatr, v. 75, n. 2, p. 123-126, 2017.

PERALES, F. J.; JIMÉNEZ, J. de D. Las ilustraciones en la enseñanza aprendizaje de las ciencias: análisis de libros de texto. Enseñanza de las Ciencias, v. 20, n.3, p.369-386, 2002.

PERREIRA, A. G.; TERRAZAN, E. A. A multimodalidade em textos de popularização científica: contribuições para o ensino de ciências para crianças. Ciência \& Educação, v. 17, n. 2, p. 489-503, 2011.

ROCHA, S.; FELTES, H. P. de M. Multimodalidade da linguagem nas campanhas de prevenção HIV/Aids: uma análise cognitiva e cultural, Signo, v. 41, n. 70, p. 75-87, 2016.

ROSE, G. Visual methodologies: an introduction to the interpretation of visual materials. London: SAGE Publications, 2001.

SANTOS, Z. B. dos; PIMENTA, S. M. O. Da semiótica social à multimodalidade: a orquestração de significados. CASA: Cadernos de Semiótica Aplicada, v.12, n.2, p. 295-324, 2014. 
SEGATTO, L. S.; KNOLL, G. F. Análise dos recursos multimodais em texto publicitário impresso. Signo, v. 38, n. 64, p. 66-83, jan./jun. 2013.

SILVA, C. M. da C. et al. Educação em saúde: uma reflexão histórica de suas práticas. Ciência \& Saúde Coletiva, v. 15, n. 5, p. 2539-2550, 2010.

SILVA, H. C. et al. Cautela ao usar imagens em aulas de ciências. Ciência e Educação, v. 12, n. 2, p. 219-233, 2006.

VALLA, V. V. Controle social ou controle público? In.: DE SETA, M. H. et al. (Org.). Gestão e vigilância sanitária: modos atuais de pensar e fazer. Rio de Janeiro: Editora Fiocruz. p. 49-60, 2006.

VALLE, D.; PIMENTA, D. N.; AGUIAR, R.. Zika, dengue e Chikungunya: desafios e questões. Epidemiol. Serv. Saúde, Brasília, v. 25, n. 2, p. 419-422, abr./jun. 2016.

VAN LEEUWEN, T.. Discourse and practice: new tools for critical discourse analysis. New York: Oxford University Press, 2008.

VASCONCELOS, E. M. Educação popular e a atenção à saúde da família. $\sigma^{a}$ ed. São Paulo: Hucitec: 2015.

\section{NOTAS}

1 A campanha pode ser acessada em: http://portalms.saude.gov.br/campanhas/26475-mosquito-nao.

2 Doença Sexualmente Transmissível foi a nomenclatura utilizada pelos GT, porém, neste trabalho utilizamos Infecção Sexualmente Transmissível (IST).

\section{Submetido em 19/04/2019}

Aprovado em 03/07/2020

\section{Contato:}

Jefferson Silva Costa

Escola Técnica Estadual Ariano Vilar Suassuna

Avenida Bom Pastos, S/N, Bairro Boa Vista

CEP 55.292-272 - GaranhunS, PE - Brasil 